\title{
Mediación familiar y conflicto: aspectos conceptuales ${ }^{1}$ \\ Family mediation and conflict. Conceptual topics ${ }^{1}$
}

\author{
Fabiola Cortez-Monroy ${ }^{2}$ y María Olga Solar ${ }^{3}$
}

\begin{abstract}
Resumen
El presente artículo aborda conceptualmente el tema de la mediación familiar como un recurso alternativo que permite a las personas enfrentar conflictos, manteniendo el control de sus vidas, y decidir según sus valores y creencias. Los conflictos se analizan desde una perspectiva positiva, como una oportunidad de transformación y crecimiento para las personas, de ahi que se enfatice en la necesidad de aprender cómo enfrentarlos de una manera constructiva. Ello implica no sólo el reconocimiento del conflicto, sino también comprender qué es, conocer sus componentes y aquellos comportamientos y actitudes que favorecen a las partes involucradas encontrar soluciones por sí mismas.
\end{abstract}

Palabras claves: familia - mediación - conflicto

\begin{abstract}
The present article develops in a conceptual manner the topic of the family mediation as a resource that allows people to face conflicts, maintaining the control of their lives, and deciding according to their values and beliefs. The conflicts are analyzed from a positive perspective, as an opportunity for the transformation and growth of the persons. That is because it is emphasized the necessity of learning how to face the problems in a constructive way. It does not only imply the recognition of the conflict, but also the understanding of it, the knowing of their components and of those behaviors and attitudes that favor the involved parts to find solutions for themselves.
\end{abstract}

Key words: family - mediation - conflict

La mediación tiene una larga historia en la mayoría de las culturas del mundo. Así por ejemplo, los filósofos griegos utilizaban el concepto de mediación en aquellos casos en que existía la necesidad de encontrar un modo de vincular dos elementos distintos. "La mediación era concebida como la actividad propia de un agente facilitador o "realidad intermedia", es decir, como la "actividad de aquel individuo que 'mediaba' o 'acercaba' dos elementos distintos. Del derecho romano se conocen los llamados jueces de avenencia, y de la época de Cicerón, los juicios de árbitros que acudían a la equidad para resolver las disputas" (Highton \& Álvarez: 1995:144).
En diversas culturas, los jefes de familias ofrecieron a sus miembros su sabiduría como un medio de ayudarles a resolver sus discrepancias. De esta forma, a través de la historia los círculos familiares extensos constituyeron un recurso de mediación. Sin embargo, "a medida que la familia nuclear empezó a reemplazar a la familia extensa, la estructura familiar comenzó a disminuir en su carácter de recurso para la resolución de conflictos, y las personas comenzaron a acudir en busca de mecanismos formales para resolver sus desavenencias" (Folberg y Taylor, 1984: 22).

1 Parte de los contenidos de este artículo se incluyeron en el material docente del Diploma "Construyendo Familia" de la P.U.C.

2 Asistente Social, Maestría en Sociología, Université Catholique de Louvain, Docente Escuela de Trabajo Social de la Universidad Católica de Chile.

3 Asistente Social, Master of Teaching Social Work, Terapeuta Familiar, Mediadora, Docente Escuela de Trabajo Social de la Universidad Católica de Chile. 
La concepción actual de mediación, surge alrededor de los años sesenta en Estados Unidos como una forma alternativa de resolución de conflictos en diferentes materias de la vida social, entre ellas la familia. En este contexto que ha sido llamado de desformalización del derecho, se legitima la mediación. "Nuestras sociedades, cada vez más complejas tienen necesidad de 'elasticidad' para escapar de las exigencias de la modernidad, sin una ruptura excesiva. Se trata de apoyarse sobre una 'lógica funcional que ya no busca principios o normas para estabilizar u ordenar una situación, como ocurre en la lógica institucional'. El derecho es considerado un conjunto de normas que no contempla lo suficiente la manera como se ponen en práctica dichas normas, tal como lo haría la mediación. Es necesario entonces, que el legislador rechace las formas canónicas jurídicas, si él desea promover este modo de regulación. Las necesidades sociales requieren ser reguladas, por dispositivos que relativicen las reglas del 'derecho formal'. De manera complementaria a esta filosofía del derecho, el 'derecho relativo' de la mediación, favorecería, la emergencia de nuevos procedimientos, flexibles y adaptados a las necesidades de regulación de nuestra sociedad postmoderna" (Le Roy, 1992: 17-18 en Ben Mrad F., 2002: 15)

\section{Mediación familiar: ¿qué es?}

En Chile, se ha reconocido el potencial de la mediación para resolver conflictos en dominios diferentes, siendo el espacio familiar uno de aquellos donde ha adquirido mayor relevancia. Ella constituye un recurso alternativo de resolución de conflictos en el que las partes reflexionan y dialogan con el objetivo de generar alternativas posibles para la resolución de sus conflictos. Es un proceso voluntario y confidencial en el que las partes asumen la responsabilidad por la construcción de las resoluciones; las personas son autoras de la solución de sus conflictos (Fonkert, 2000: 109).

En el ámbito familiar la mediación se presenta como una opción que trabaja con los recursos de la familia para resolver competentemente las situaciones novedosas que se presentan frente a crisis y cambios de muy diferente índole: normativos, evolutivos, contextuales. La mediación familiar cubre la problemática de las parejas que se divorcian -regulación del tiempo que cada progenitor pasa con los hijos, progenitor a cargo, división de bienes, etc.- y otras situaciones vinculadas con sucesiones, empresas familiares o conflictos ligados al ciclo de vida que surgen con los adolescentes o en la tercera edad (Fonkert, 2000).

Para M. Guillaume-Hofnung (1995) la mediación constituye un modo de construcción y de gestión de la vida social gracias a la intervención de un tercero, neutro, independiente sin otro poder que la autoridad que le reconocen las personas que lo han elegido libremente. La finalidad de la mediación es ayudar a las personas a encontrar por sí mismas las soluciones a sus problemas.

De esta forma, en el dominio familiar, la mediación puede ser entendida como "un método de resolución de conflictos, basado en la cooperación y por el cual un tercero imparcial y calificado ayuda a los miembros de la familia a elaborar por sí mismos un acuerdo viable y satisfactorio para cada uno" (La Brie, Langlois, 1992: 13). Se trata de un modelo de intervención que puede "ayudar a la familia a mantenerse, a reequilibrarse, a evolucionar" (Brisson, 1992: 215).

Las necesidades de las personas constituyen el eje del modelo de la mediación. La idea es poner en evidencia, "inventariar" las necesidades de cada uno de los miembros de la familia. Sobre la base de estas necesidades que, representan, a su vez, los intereses de las personas, se negocia. La mediación se dirige a que las partes, con la ayuda de un tercero imparcial (mediador), busquen una solución al conflicto o crisis que está viviendo la familia, solución que debe ser satisfactoria para cada uno de sus integrantes.

Dar poder a las personas es la piedra angular de la mediación. La mediación facilita, permite que las personas asuman su situación y sus responsabilidades. Les permite mantener el control de sus vidas y decidir según sus valores y creencias. En esta mirada, el mediador no es responsable del acuerdo final (Brisson \& Michea, 1997: 16). Él es el responsable de conducir un proceso que facilite el surgimiento de alternativas de solución frente a las necesidades expresadas por las personas en mediación. La mediación busca potenciar la autodeterminación, la comunicación y la responsabilidad de los individuos. De esta forma, el mediador es responsable del proceso, pero no del resultado.

\section{Ventajas de la mediación}

La mediación, generalmente, es presentada como un sistema alternativo de resolución de conflictos, que se distinguiría de un sistema adversarial (por ejemplo, juicio), en que en este último es "otro", no 
involucrado en el conflicto, aquel que decide la "resolución" del mismo. En reiteradas ocasiones esta forma de enfrentar los conflictos puede no satisfacer a las partes, por lo cual el conflicto puede continuar, aún después de la sentencia judicial. La mediación busca terminar con el litigio, pero sin litigar, diluyendo las figuras de los de vencidos y vencedores, transitando desde una lógica ganar - perder a otra de ganar - ganar.

Para que esta nueva lógica del ganar - ganar pueda desarrollarse, es necesario que se potencien nuevas formas de relación entre las personas en conflicto, de manera que se logre movilizarlas desde una posición adversarial hacia otra más colaboradora y empática, lo que permite a ambas co-construir el acuerdo para resolver el conflicto. Desde esta perspectiva, se puede decir que la mediación es una práctica social, que implica un compromiso en la resolución de los conflictos a través del diálogo. Diálogo que necesita que los participantes se aúnen en el desarrollo de nuevas visiones de realidad, desde las cuales cambien su posición, dejando de combatir para empezar a colaborar. Al encaminarse hacia un objetivo común, cada uno redefine al otro y ambos ponen los cimientos de una concepción del nosotros (Fried Schnitman, 2000: 18)

Es así como en materia de familia y, especialmente en conflictos de pareja, la mediación presenta ventajas en relación con el litigio. Rodríguez y Padilla (2003) resumen en el siguiente cuadro las diferencias que presenta la mediación con respecto al juicio.

Folberg y Taylor (1984) señalan que la forma más útil de comprender la mediación es considerarla como una intervención de solución de problemas dirigida a una meta. Meta que no necesariamente es la resolución del conflicto, ya que si bien la mediación tiene el propósito de resolver desavenencias y reducir el conflicto, proporciona también un espacio de reflexión para la toma de decisiones. Esto significa que, incluso en el caso en que no puedan resolverse todas las diferencias, en el proceso de mediación las partes tendrán la posibilidad de dialogar, de escucharse, de expresar sus opiniones e intereses, de tal forma que es posible que lleguen a entender la causa esencial del conflicto y puedan reducirla a un nivel manejable, menos conflictivo. De aquí entonces, que la mediación para estos autores, sea entendida como un proceso de manejo de conflicto que permite:

\section{CUADRO COMPARATIVO ENTRE MEDIACIÓN Y JUICIO}

\begin{tabular}{|c|c|}
\hline Mediación familiar & Juicio \\
\hline - Promueve la comunicación y la colaboración & - Promueve la confrontación y mantiene el conflicto \\
\hline - Desde el principio orientas las acciones hacia el futuro & $\begin{array}{l}\text { - Como no toma en cuenta los conflictos emocionales, } \\
\text { la pareja se mantiene estancada en sus desacuerdos } \\
\text { por mayor tiempo }\end{array}$ \\
\hline $\begin{array}{l}\text { - Permite que la pareja tome sus propias decisiones y, } \\
\text { por lo tanto, que los acuerdos sean más duraderos }\end{array}$ & $\begin{array}{l}\text { - Deja las decisiones sobre el futuro de la pareja y la } \\
\text { familia en manos de los abogados y el juez }\end{array}$ \\
\hline $\begin{array}{l}\text { - El mediador está del lado de toda la familia, } \\
\text { principalmente de los niños }\end{array}$ & $\begin{array}{l}\text { - El abogado considera que los cónyuges son } \\
\text { adversarios y su obligación es el triunfo de su } \\
\text { defendido }\end{array}$ \\
\hline $\begin{array}{l}\text { - Ofrece un espacio privado y confidencial } \\
\text { para que la pareja pueda expresarse }\end{array}$ & $\begin{array}{l}\text { - Expone a la pareja a exhibir públicamente } \\
\text { sus desavenencias }\end{array}$ \\
\hline - Preserva la relación futura de la pareja & $\begin{array}{l}\text { - Destruye cualquier relación previa y limita las } \\
\text { posibilidades de un entendimiento futuro }\end{array}$ \\
\hline $\begin{array}{l}\text { - Utiliza el conflicto como la posibilidad de } \\
\text { crecimiento personal y cambio positivo }\end{array}$ & $\begin{array}{l}\text { - Utiliza el conflicto como la oportunidad } \\
\text { para definir vencedores y vencidos }\end{array}$ \\
\hline - Reduce los costos del proceso legal & - Es costoso \\
\hline - Es un proceso ágil & - Puede durar años \\
\hline
\end{tabular}

Rodríguez B., Padilla de Trainer M., Mediación en el divorcio. México, UNAM, 2001, pp. 24. 
- Reducir los obstáculos a la comunicación entre los participantes.

- Realizar al máximo la exploración de alternativas.

- Atender a las necesidades de todos los que en ella intervienen.

- Proporcionar un modelo para la futura resolución de conflictos en contextos sociales diferentes. Marinés Suares (1996) además de reconocer este atributo de la mediación, destaca como ventajas:

- Alivio a los tribunales, esto porque muchos casos se resuelven, aún sin haber ingresado al sistema judicial tradicional.

- Ahorro de tiempo y de dinero para las personas. Dado el modo como se conduce el conflicto (a través de reuniones entre el mediador y las partes involucradas), la mediación evita las demoras que un juicio trae aparejado (presentación de pruebas, testigos entre otros). El proceso se inicia cuando las partes acceden a participar y los días y horarios de reunión son determinados en conjunto con el mediador. En cuanto al dinero, la mediación resulta mucho más económica que los procesos judiciales formales, puesto que existen instancias en las que el servicio es gratuito y porque se ahorran los costos asociados al mantenimiento de un juicio durante meses e incluso años.

- Evita que haya ganadores y perdedores, lo que favorece el mantenimiento de las relaciones futuras entre las personas.

- Aumenta el protagonismo y responsabilidad de las partes, puesto que son ellos quienes deciden como resolver sus diferencias, sin que sea un tercero que les indique como proceder o qué acordar.

Es posible señalar, entonces, que la mediación es un proceso en el cual se potencia una mayor colaboración y un mayor compromiso, asumiendo las responsabilidades que cada uno de los involucrados ostenta en la construcción de los conflictos y en la resolución de éstos, desde una postura protagónica.

\section{Principios de la mediación}

El proceso de mediación tiene principios sobre los cuales se fundamenta. Estos principios, si bien no garantizan el alcance de acuerdos y tampoco su cumplimiento, contribuyen a potenciar en las personas capacidades y habilidades que les permitan desarrollar acuerdos creativos, coherentes con sus necesidades e intereses.

Voluntariedad: se relaciona con la libertad de las personas para decidir si participan o no del proceso. El mediador no cuenta con la autoridad para obligar a las personas a mantenerse en el proceso, en este sentido se habla de que no existen medios coercitivos que les obliguen a participar y a permanecer en el sistema. Para que las personas decidan voluntaria y libremente su participación es imprescindible que se encuentren informadas sobre el servicio que se prestará. La importancia de este supuesto no sólo radica en la expresión de la libertad y autonomía de las personas, sino también en el impacto posterior que generará en el proceso de acuerdo, ello porque "en la medida que el proceso es voluntario, asegura el mayor compromiso o interés en resolver el problema que afecta a las partes" (Arrué et al, 1997).

Protagonismo: alude a la capacidad que las personas participantes de mediación tienen para sentirse y considerarse autores, agentes de las acciones que se desarrollan y de los discursos y narrativas que se construyen. Además, implica sentirse responsable por las consecuencias buenas o malas de las acciones llevadas a cabo o de los dichos que cada uno manifiesta (Suáres, 2002).

Por otra parte, el protagonismo también implica que el profesional mediador, que guía el proceso, reconozca en los participantes sus capacidades y fortalezas para asumir su proceso de resolución de conflictos.

Confidencialidad: Junto con ser uno de los principios rectores del proceso de mediación es, también una de las ventajas que ofrece en comparación a otras instancias judiciales, como la conciliación judicial. En mediación, las personas gozan de entera libertad para manifestar sus intereses y sus necesidades, su percepción del conflicto y de la relación, sin temor a que el mediador (como receptor de ciertas confidencias), sea el que finalmente resuelva y acuerde, si ellos no logran hacerlo. Por esto mismo, permite a las partes estar seguras y confiadas de que nada de lo que dicen será usado en su contra en caso de no alcanzar acuerdo en mediación y deban recurrir a un tribunal. "Un requisito ineludible del proceso, es que las partes y el mediador puedan comunicarse con total libertad. Para ser efectivo, el mediador, debe poder solicitar información y hacer preguntas que no serían contestadas si existiera el peligro de utilización posterior fuera de contexto" (Palma, 1999 en Arrué et al, 1997: 45). 
La confidencialidad implica reserva también, sobre los que las partes comunican en las reuniones individuales. Sólo si ellas lo permiten, el mediador puede poner sobre la mesa en las reuniones conjuntas, los temas abordados en las sesiones individuales.

Mantener la confidencialidad durante el proceso de mediación no responde sólo a una característica procedimental de ésta, sino que también es considerada una norma o deber ético del mediador. Sin embargo existen ciertas excepciones en las que se debe y puede romper el compromiso. La confidencialidad no se extiende a la información relativa a la comisión de un crimen o a la violencia sobre - o abuso de- niños o niñas.

Neutralidad: Alude a la imparcialidad y equidistancia del profesional respecto del conflicto y de las partes involucradas. El mediador es un tercero imparcial, en tanto, no actúa unilateralmente a favor de una de las partes. La imparcialidad está vinculada con la posición del mediador, que no debe favorecer a ninguna de las partes. La equidistancia puede ser entendida como "estar a igual distancia", es decir, no acercarse más a uno que a otro, no tener diferentes distancias con las partes (Suares, 1996: 151).

Aún cuando se reconoce la imposibilidad de neutralidad absoluta en ningún acto de la vida de las personas, el mediador debe contar con la capacidad y habilidad que le permita abordar los conflictos de las personas sin mostrar preferencia e inclinación por ninguna de ellas.

Respeto: Supuesto básico de toda relación, que implica reconocer al otro como un otro con necesidades, intereses y posiciones tan válidas como las propias. El respeto va acompañado de la capacidad de escuchar el mensaje de aquél con cual no hay consenso.

Colaboración/Cooperación: aún cuando ambos conceptos son usados indistintamente, es preferible referirse a la cooperación en mediación, pues es este término el que describe el compromiso que asumen las partes para intentar lograr un acuerdo, a lo cual contribuye el carácter voluntario del proceso. La cooperación en mediación implica dejar de lado la confrontación para la búsqueda de una salida a la disputa. Cooperar se usa en el sentido de operar con el otro. Alude a un equipo que trabaja en conjunto para resolver un tema en conflicto.

Diálogo: a través del diálogo las partes aprenden a resolver sus conflictos. La intervención mediadora es definida como un proceso lingüístico, en el cual se ofrece a los participantes un espacio conversacional. Dar espacio a procesos de definición de significados, apoyados en técnicas como parafraseo, resúmenes, reformulaciones, reencuadres, revalorizaciones y preguntas, entre otros.

Deuteroaprendizaje: es un principio poco mencionado en el proceso de mediación. Deutero proviene del griego, y significa segundo o secundario. En consecuencia, deuteroaprendizaje significa segundo aprendizaje, alude a la adquisición de capacidades que permitan solucionar conflictos futuros. En este sentido la mediación habilita para resolver conflictos futuros, por otra parte, potencia en los sujetos capacidades como constructores y autogestores de sus vidas, de sus problemas y de sus soluciones.

El deuteroaprendizaje es un producto esperado del proceso de mediación, pero no se aprecia en el proceso mismo, sino que se manifestaría al enfrentar conflictos futuros., en los cuales las personas pueden hacer uso de lo aprendido, intentando resolverlos por su propios.

Acento en el futuro: la mirada hacia el futuro le da un carácter dinámico y fluido al proceso, importa más el futuro que el pasado. Si bien existe la opción de revisar el pasado, con lo cual se deja anclado el presente, también se observa la capacidad de abrir futuro a través de la conversación, construyendo conjuntamente realidades y soluciones. Esto no significa que se reniegue del pasado, en la medida que por éste las partes se encuentran en mediación. Se trata de orientar la conversación hacia el futuro.

Si bien estos principios funcionan armónicamente complementándose unos con otros, se diferencian en tanto algunos están referidos al proceso, otros a los deberes éticos de los mediadores, y los últimos son aquellos relativos a las partes y otras personas que participan en el proceso (MINJU, 2000).

Dentro de los principios éticos rectores del proceso encontramos la promoción del protagonismo de las partes y del trabajo en conjunto para resolver por ellos mismos sus diferencias; igualdad de las partes; restablecimiento de la comunicación; autonomía y respeto por las ideas de los otros.

En cuanto a los principios relativos al desempeño profesional de los mediadores, se destacan la imparcialidad (actitud de equidistancia entre las partes); confidencialidad, que alude a la prohibición ética de divulgar o ventilar asuntos tratados en mediación; deber de objetividad que implica la realización de su labor de manera responsable y basándose en el manejo de técnicas y habilidades. 
Por último en lo que respecta a los principios éticos de las partes, se espera que éstos mantengan una actitud de cooperación en el transcurso del proceso, que éste se realice en un ambiente de respeto; que haya honestidad en el planteamiento del conflicto, intereses y necesidades, que exista una actitud activa, flexible y perseverante y que se ponga énfasis en el futuro.

\section{Conflicto y mediación familiar}

La mediación familiar desarrolla métodos a fin de tratar conflictos ligados a la vida en común, pasada o presente, en tanto ellos emergen de una historia compartida (Milburn, 2002: 73).

Los conflictos son situaciones en que dos o más personas entran en oposición o desacuerdo, porque sus posiciones intereses, necesidades, deseos o valores son incompatibles o son percibidos como incompatibles, donde juegan un papel muy importante las emociones y los sentimientos, y donde la relación entre las partes en conflicto pude salir robustecida o deteriorada en función de cómo sea el proceso de resolución del conflicto (Torrego, 2000: 37). El conflicto no necesariamente debe ser percibido de manera negativa, pues también puede representar una oportunidad de transformación y crecimiento para las personas.

Ahora bien, todo acto de mediación presupone la existencia de un conflicto o discrepancia, pero no todo conflicto implica un acto de mediación (De Tommaso, 1997: 31). La mediación contribuye a regular las relaciones familiares en el marco de diferentes procesos (separación conyugal, relaciones padres e hijos, entre hermanos, etc.), con el propósito de preservar el interés de cada uno de los miembros de la familia.

En el campo de la mediación, el conflicto es definido por Suares (1996) como un proceso interaccional evolutivo que, como tal, nace, crece y se desarrolla, que se da entre dos o más partes, en el que predominan las interacciones antagónicas y en el que los involucrados intervienen como seres totales (con sus sentires, pensares y haceres). Se caracteriza por ser un proceso co-construido por las partes, que en ocasiones puede manifestarse de manera agresiva y que puede ser conducido por los implicados o por un tercero.

Si bien se conocen como conflictos, Suares (1996), hace hincapié en que deberían ser llamados procesos conflictivos, puesto que presentan diferentes etapas o estados. Autores como Folberg y Taylor
(1992) señalan que es posible establecer cinco fases en la vida de un conflicto:

1. El conflicto latente: existe cuando hay solo una estructura de conflicto generada por la existencia de intereses que se oponen de manera recíproca. El conflicto puede permanecer latente indefinidamente.

2. La iniciación del conflicto: el conflicto se activa cuando sucede un acontecimiento que lo desencadena (conflicto manifiesto).

3. La búsqueda de equilibrio del poder: las partes en conflicto buscan equilibrar sus posiciones a través del uso de la fuerza o de medios coercitivos. Sin embargo, también pueden hacerlo mediante métodos colaborativos como la mediación.

4. El equilibrio de poder: ambas partes encuentran un punto medio en el que ven satisfechas parte de sus demandas y/o necesidades, esto a través de procesos de resolución de conflictos.

5. La ruptura del equilibrio, se da cuando las condiciones que permitieron el equilibrio de poder y alcance de acuerdo en algunos casos, varían en el tiempo generando nuevas rupturas.

Desde lo anterior es posible conceptuar el conflicto como una divergencia de intereses, la cual es percibida por las partes. Los intereses constituyen sentimientos de las personas acerca de lo que es básicamente deseable, razón por la cual tienden a estar en el centro de sus pensamientos y de sus acciones, formando así, el núcleo de muchas de sus actitudes, metas e intenciones. Son los intereses los que motivan a las personas constituyéndose en el resorte silencioso que subyace en el conflicto (Highton y Alvárez,1995: 42-43). En palabras de Torrego (2000: 39), los intereses son los beneficios que deseamos obtener a través del conflicto.

Subyacen a los conflictos necesidades insatisfechas, las que suelen estar detrás de los intereses. Para MaxNeef (1994), las necesidades humanas revelan de la manera más apremiante el ser de las personas, ya que éste se hace palpable a través de ellas en su doble condición experimental: como carencia y como potencialidad. Comprendidas en un amplio sentido, y no limitadas a la mera subsistencia, las necesidades patentizan la tensión constante entre carencia y potencia tan propia de los seres humanos. Concebir las necesidades tan sólo como carencias implica restringirlas a lo puramente fisiológico o subjetivo, que es precisamente el ámbito en que una necesidad asume 
con mayor fuerza y claridad la sensación de "falta de algo". Sin embargo, en la medida en que las necesidades comprometen, motivan y movilizan a las personas, son también potencialidades y, más aún, pueden llegar a ser recursos. Enfrentar los conflictos de una manera inadecuada, conlleva insatisfacción necesidades y muchas veces frutración, la que puede ir acompañada de sentimientos de tristeza, ira, temor, entre otros.

Por otra parte, Torrego (2000: 39) distingue las posiciones. Éstas corresponden al estado inicial de las personas frente a un conflicto. Es lo que inicialmente reclama cada parte. Según ellas, responder a sus posiciones les hará sentirse satisfechos. Responden a la pregunta ¿qué quieres?. Las posiciones suponen la cubierta de lo intereses y, frecuentemente, inhiben la comprensión del problema.

Centrarse en el análisis de las posiciones no es fructífero, pues detrás de ellas siempre vamos a encontrar necesidades, que como ya se señaló revelan de la manera más apremiante el ser de las personas.

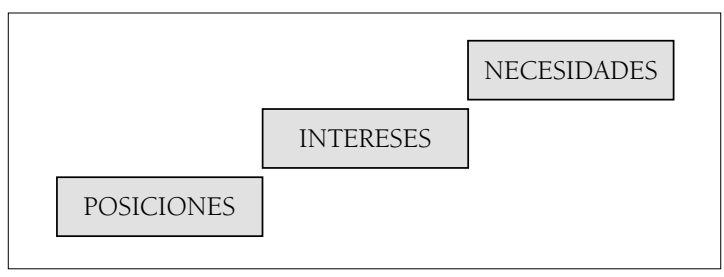

Por lo anterior en mediación familiar es necesario que, luego de conocer las posiciones de cada parte, se identifiquen los intereses y las necesidades de éstas, de modo de lograr una mejor negociación.

Cualquier método de negociación debe juzgarse conforme a tres criterios: debe conducir a un acuerdo sensato si el acuerdo es posible. Debe ser eficiente. Y debe mejorar o por lo menos no deteriorar la relación entre las partes. (Un Acuerdo sensato, puede definirse como aquel que satisface los interese legítimos de ambas partes dentro de lo posible, que resuelve los conflictos de intereses con equidad, que es durable, y que tiene en cuenta los intereses de la comunidad (Fisher R., Ury W., Patton B., 1994: 4).

\section{Clasificación de los conflictos}

Los conflictos se pueden clasificar según el tipo de sistemas involucrados, y entre éstos es posible distinguir distintos niveles de conflictos (Rodríguez, 2001: 193):

\begin{tabular}{|c|c|c|}
\hline $\begin{array}{l}\text { Contexto del } \\
\text { Conflicto }\end{array}$ & $\begin{array}{l}\text { Conflicto interno } \\
\text { al sistema }\end{array}$ & $\begin{array}{l}\text { Conflicto entre } \\
\text { Sistemas }\end{array}$ \\
\hline \multicolumn{3}{|l|}{$\begin{array}{l}\text { Nivel de } \\
\text { conflicto }\end{array}$} \\
\hline Individuo & $\begin{array}{l}\text { Conflicto } \\
\text { intrapersonal }\end{array}$ & $\begin{array}{l}\text { Conflicto } \\
\text { interpersonal }\end{array}$ \\
\hline Grupo & $\begin{array}{l}\text { Conflicto } \\
\text { intragrupal }\end{array}$ & $\begin{array}{l}\text { Conflicto } \\
\text { intergrupal }\end{array}$ \\
\hline Organización & $\begin{array}{l}\text { Conflicto interno } \\
\text { a la organización }\end{array}$ & $\begin{array}{l}\text { Conflicto } \\
\text { entre } \\
\text { organizaciones }\end{array}$ \\
\hline Estado & $\begin{array}{l}\text { Conflicto } \\
\text { intranacional }\end{array}$ & $\begin{array}{l}\text { Conflicto } \\
\text { internacional }\end{array}$ \\
\hline
\end{tabular}

En el conflicto intrapersonal el individuo se siente presionado por expectativas o demandas contradictorias. En su origen está la presión por la decisión. Lewin (1951 en Rodríguez, 2001: 193) clasifica estas decisiones conflictivas en tres categorías:

\begin{tabular}{|c|l|}
\hline $\begin{array}{c}\text { - Atracción/ } \\
\text { Atracción }\end{array}$ & $\begin{array}{l}\text { Elección entre dos alternativas } \\
\text { igualmente atractivas }\end{array}$ \\
\hline $\begin{array}{c}\text { - Atracción/ } \\
\text { Rechazo }\end{array}$ & $\begin{array}{l}\text { Elección de un curso de acción } \\
\text { desagradable a cambio de un premio o } \\
\text { recompensa que es atractivo. }\end{array}$ \\
\hline $\begin{array}{c}\text { - Rechazo/ } \\
\text { Rechazo }\end{array}$ & $\begin{array}{l}\text { Elección de un curso de acción } \\
\text { desagradable para evitar el castigo o una } \\
\text { situación también desagradable }\end{array}$ \\
\hline
\end{tabular}

También es posible clasificar los conflictos según la visibilidad en:

- Conflictos latentes

- Conflictos manifiestos

Como se señaló anteriormente, de acuerdo a Folberg y Taylor, 1992 se habla de conflicto latente cuando existe sólo una estructura de conflicto caracterizada por la presencia de intereses opuestos entre las personas y, si bien existen diferencias entre éstas, el conflicto propiamente tal, aún no se manifiesta. Un conflicto puede mantenerse latente indefinidamente, siendo posible y esperable que suceda algún acontecimiento que lo desencadene y permita su manifestación. Cuando esto sucede, el conflicto se ha vuelto manifiesto para las partes y también para quienes les rodean.

"El conflicto latente es desconocido y, por consiguiente no puede ser tratado. Una de las formas de intentar el tratamiento de un conflicto latente 
estriba en buscar formas de hacerlo manifiesto" (Rodríguez, 2001: 202)

Otras clasificaciones, nos permiten agrupar los conflictos según:

- La frecuencia: conflictos esporádicos, escasos y permanentes.

- El tipo: conflictos de valores, de intercambios, de metas, de distribución, entre otros.

Se entiende por resolver los conflictos el proceso que, a diferencia de manejarlos o gestionarlos, nos conduce hasta sus causas profundas. No obstante, la resolución de un conflicto no implica que a continuación no surjan otros. En la medida en que se interacciona, siguen apareciendo conflictos que ofrecen oportunidades para avanzar o retroceder, dependiendo de cómo se enfrenten y los caminos de solución que se escojan.

El reto que plantea, entonces, el reconocimiento de los conflictos en la vida cotidiana de los individuos y su importancia en el desarrollo de las relaciones y el mantenimiento de la sociedad, será aprender a cómo enfrentar y resolverlos de una manera constructiva. Esto implica no sólo el reconocimiento del conflicto, sino también comprender qué es el conflicto y conocer sus componentes, así como desarrollar actitudes y estrategias que permitan resolverlos.

\section{Visión positiva del conflicto}

Highton y Alvárez (1995) señalan que en las últimas décadas la sociedad ha comenzado a considerar el conflicto desde una visión positiva, como generador de energía, fuerza y un elemento vitalizador de la innovación y el cambio. Incluso señalan que el conflicto es deseable, en la medida que de existir, significa que los seres humanos están en relación, en contraste con la indiferencia.

Desde este enfoque el conflicto presenta importantes beneficios como factor de cambio, de hecho se señala que "en muchos casos, las diferencias interpersonales, la competencia, la rivalidad y otras formas de conflicto tienen un valor positivo para los participantes y para el sistema social o la organización donde ocurren. Un nivel moderado de conflicto interpersonal puede aumentar la motivación y la energía: el conflicto puede alentar la innovación de los individuos y del sistema gracias a que propicia una mayor diversidad de puntos de vista (...) permitiendo a las personas, conocer mejor las propias posiciones ya que el conflicto les obliga a fundamentar y a sustentar los argumentos en que se apoyan" (Walton, 1988, en: Higthon y Alvárez, 1995: 47).

Otros beneficios del conflicto son ( Pruitt y Rubin, 1992: 23):

- Al ejercer presión a favor de la innovación, la creatividad y la transformación de las relaciones, se opone a la osificación del sistema.

- Al abordar los conflictos en toda su complejidad es más probable obtener mejores soluciones. Por el contrario, si se impide el curso natural de un conflicto, se puede llegar a tomar decisiones prematuras sinónimo de decisiones pobres y de peores soluciones.

- Enfrentar los conflictos, es necesario para alcanzar la justicia. Desde el sistema social más pequeño y en situaciones de desequilibrio de poder, en ocasiones se impide que el conflicto emerja, lo que da lugar a situaciones de opresión y de injusticia.

Desde esta visión positiva del conflicto éste no sería el problema, sino la forma de enfrentarlo. El énfasis está puesto, entonces, en como reaccionamos frente a una situación conflictiva

\section{Estilos de enfrentar conflictos}

Cuando un conflicto se hace manifiesto es posible distinguir en las personas ciertos comportamientos o conductas típicas: competir o contender; ceder o conceder; convenir; colaborar y resolver problemas; evitar, no hacer nada o retirarse (Torrego 2000; Higthon y Alvárez, 1995). Estos comportamientos no son excluyentes, sino más bien constituyen estrategias que pueden ser usadas por las partes en conflicto en distintos momentos de éste, y son productos de la relación que se da entre dos variables que intervienen en un conflicto, a saber:

- la preocupación por los objetivos y metas propios,

- la preocupación por los deseos del otro u otros.

En la práctica estos modos de enfrentar surgen debido a la combinación de ambas variables y de la importancia que las personas le dan a cada una de ellas.

1. Competir o contender: perseguir los objetivos personales a costa de los otros, sin detenerse a pensar en los demás. "El que usa esta estrategia, trata de resolver el conflicto en sus propios términos, mantiene sus propias aspiraciones y trata de persuadir al otro para que ceda. Hay diversas formas de tratar 
de imponer la solución preferida por la propia parte a la contraria. Las tácticas incluyen las amenazas, los castigos o represalias que pueden quedar sin efecto sin el otro se allana" (Highton y Alvárez, 1995: 72)

2. Acomodarse, ceder o conceder: supone supeditar los propios deseos, anhelos y satisfacciones a los de la otra parte. Uno resigna parte de sus aspiraciones y el otro las satisface.

3. Contemporizar o convenir: alude a un claro regateo en el que se observan ofertas y contraofertas. Existe una concesión parcial por parte de las personas involucradas en el conflicto, de este modo ambos ceden algo de su posición originaria para acordar con el otro y satisfacer alguno de sus propósitos. Ambas se acomodan y logran diseñar un acuerdo.

4. Colaborar y resolver problemas: implica un nivel de unos y otros en la búsqueda de un objetivo, supone explorar el desacuerdo, generando alternativas comunes que satisfagan a ambas partes. Se parte del convencimiento que es factible y además deseable, desde un plano de reflexión ético, superar la aparente dicotomía entre lo "mío" y lo "tuyo". (Torre- go, 2000: 45). Si al convenir las partes se dividen el campo de la negociación, cuando se logra la colaboración este campo se amplía. Este comportamiento ha de satisfacer a todos los involucrados, en todos o la mayoría de sus intereses reales. Para lograrlo "las partes deberán trabajar juntas para trascender la posición originaria -de la primera oferta y contraoferta- haciendo una investigación real de los intereses y necesidades que hay detrás de ellas, generando nuevas alternativas, con lo que se incrementará el campo de la negociación" (Higthon y Alvárez, 1995: 73)

5. Evitar, no hacer nada o retirarse: actitud básica que se caracteriza por no afrontar los problemas; se evitan o posponen los problemas. Esto demuestra desinterés tanto por la metas propias como por la del otro $\mathrm{u}$ otros. Evitar, puede constituir en ocasiones, una estrategia temporal que deja abierta la posibilidad de reasumir el conflicto y otra conducta en el futuro. Sin embargo, evitar también puede implicar el abandono definitivo del conflicto.

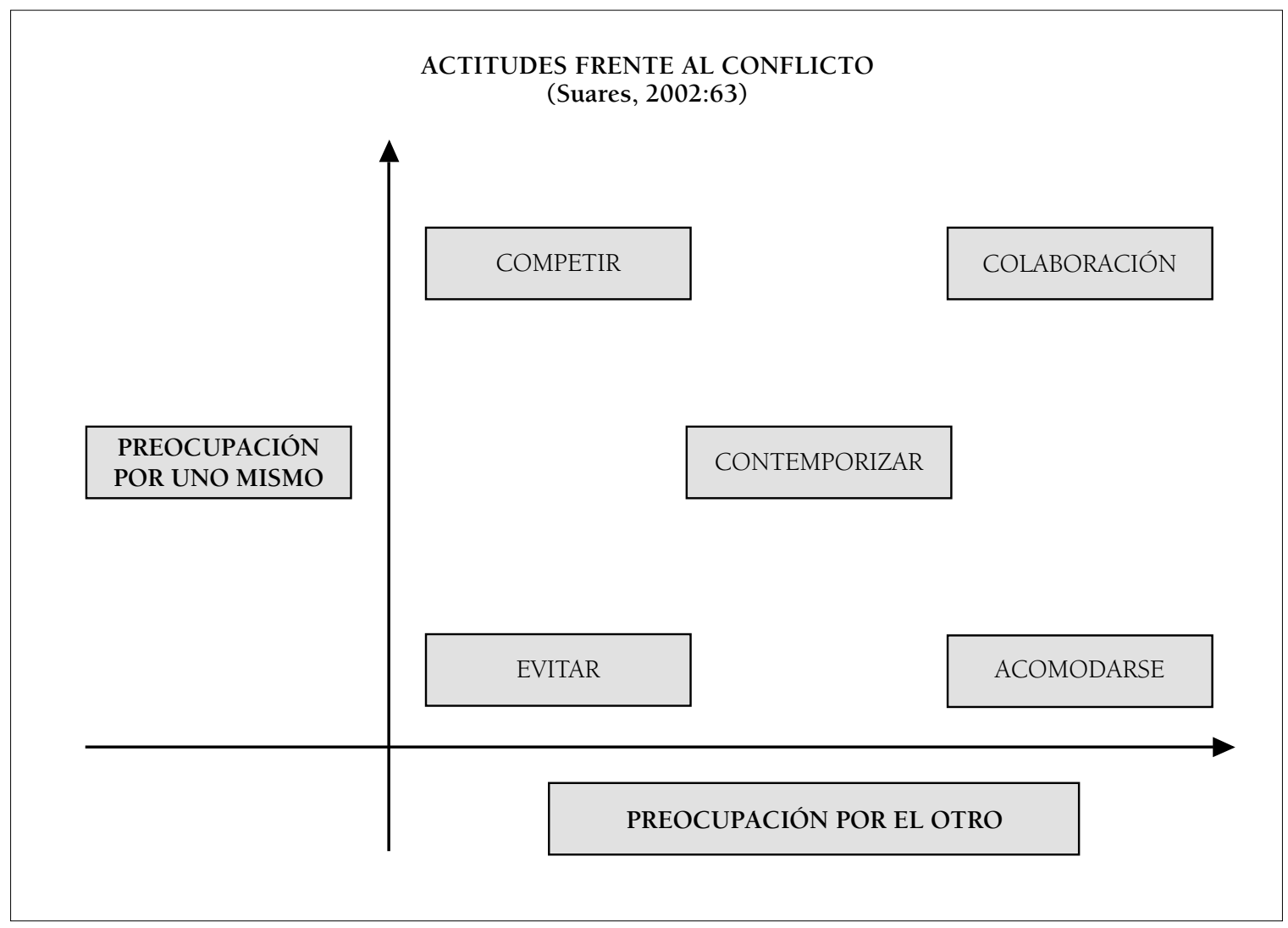


Finalmente, al enfrentarse a un conflicto conviene tener presente algunas premisas que al respecto identifica Laurent-Boyer (1992):

- El conflicto puede ser positivo. Esta premisa es coherente con la concepción moderna de los conflictos, la que preconiza la necesidad del conflicto como un elemento de la calidad de vida de toda organización. En esta perspectiva, el conflicto no debe ser evitado o suprimido, sino más bien administrado con eficacia (Lévesque, 1992: 5).

- Ante la presencia de un conflicto, casi todas las personas desean llegar a un acuerdo.

- Los mejores acuerdos se logran cuando negocian las mismas personas implicadas en el conflicto.

- La mediación en conflictos familiares debe considerar el presente, pero también debe estar orientada hacia el futuro, de modo que los acuerdos reflejen cabalmente las necesidades de las partes.

- Las necesidades y las condiciones de vida de las partes en conflicto cambian, por lo tanto es importante de considerar un mecanismo de revisión permanente.

\section{Bibliografía}

ARRUÉ, A. et al, Investigación exploratoria acerca del proceso y resultados de la aplicación de la mediación como técnica alterativa de resolución de conflictos en el ámbito judicial. Estudio de Finalización de carrera, Santiago, P. Universidad Católica de Chile, Escuela de Trabajo Social, 1997.

BEN MRAD, F., Sociologies des practiques de médiation. Entre principes et compétences, Paris, L'Harmattan, 2002.

DE TOMMASO A, Mediación y Trabajo Social, Buenos Aires, Espacio, 1997.

Diccionario de Mediación disponible en http://www.diccionariomediacion.es.vg/
FISHER R., URY W., PATTON B., Sí ... ¡De a cuerdo!. Cómo negociar sin ceder, Colombia, Carvajal S.A., 1994.

FOLBERG J., TAYLOR A., Mediación. Resolución de conflictos sin litigio, México, Limusa, 1992.

FONKERT R., Mediación padres adolescentes: recurso alternativo a la terapia familiar de conflictos en familias con adolescentes, en Fried Schnitman, D., Schnitman J. (Compiladores) Resolución de conflictos. Nuevos diseños, nuevos contextos, Buenos Aires, Granica, 2000

FRIED SCHNITMAN, D. (Compilador) Nuevos paradigmas en la resolución de conflictos. Perspectivas y prácticas, Buenos Aires, Granica, 2000.

GUILLAUME-HOFNUNG M., La Médiation, Paris, Que sais-je, PUF, 1995.

HIGHTON, E. Y ÁLVAREZ, G., Mediación para resolver conflictos, Buenos Aires, Ad- Hoc, 1995.

LEDERACH J., ABC de la paz y los conflictos, Madrid, Catarata, 2000.

LEVESQUE J., Lutilisation positive des conflits et la mediation, en Intervention, Revue de la Corporation Professionnelle des Travailleurs Sociaux du Québec, $N^{\circ}$ 91, mars 1992.

LOURENT-BOYER L., La médiation familiale: définition, cadre théorique, bienfaits, pour la famille et étude de modèles, en Lourent-Boyer L. (coordinadora), La médiation familiale, Québec, Yvon-Blais, 1992.

MAX-NEEF M., Desarrollo a escala humana, Barcelona, Icaria, 1994.

MILBURN P, La médiation: expériences et compétences, Paris, La Découverte, 2002.

MOORE, C.: "The Mediation Process", San Francisco, California, Jossey Bass Publishers, 1996.

RODRÍGUEZ, DARÍO. Gestión Organizacional. Elementos para su estudio. Ediciones Universidad Católica de Chile. Santiago de Chile, 2001.

SUARES M, Mediación, conducción de disputas, comunicación y técnicas, Buenos Aires, Paidós, 1996.

TORREGO J. (Coordinador), Mediación de conflictos en instituciones educativas, Madrid, Narcea, 2000.

FECHA DE RECEPCIÓN: diciembre 2005

FECHA DE ACEPTACIÓN: marzo 2006 